\title{
NIPPON ICHI! O ESPORTE NA CULTURA DOS ANIMES E MANGÁS
}

\author{
NIPPON ICHI! SPORTS IN ANIME AND MANGA CULTURE
}

NIPPON ICHI! EL DEPORTE EN LA CULTURA DEL ANIME Y DEL MANGA

\section{Gilson Cruz Junior*}

\section{Palavras chave:} Esportes.

Anime.

Mangá.

Keywords:

Sports.

Anime.

Manga.

\begin{abstract}
Resumo: Este ensaio discute algumas das inserções do esporte no contexto dos animes e mangás, aqui entendidos como mercadorias e ao mesmo tempo pontos de confluência de forças culturais globais e locais. Para fundamentar essa reflexão, também estabelece marcos referentes à cultura japonesa e à ascensão do esporte no Japão. Nesse sentido, infere que, apesar da forte influência exercida por símbolos pertencentes à identidade nipônica, a representação do esporte nos animes e mangás está cada vez mais próxima da (pós-)modernidade ocidental, graças à globalização e à transnacionalização de bens imateriais.
\end{abstract}

Abstract: This essay discusses some instances of the presence of sports in animes and mangas, here understood as both commodities and confluence points for global and local cultural forces. In order to support this reflection, it also sets some milestones related to Japanese culture and the rise of sports in Japan. It finds that despite strong influence exerted by Japanese identity symbols, sports' representation in animes and mangas is getting closer to western (post) modernity due to globalization and transnationalization of immaterial goods.

Palabras clave: Deportes.

Anime.

Manga.
Resumen:En este trabajo se analizan algunas de las inserciones deportivas en la cultura del anime y del manga, aquí entendidos como mercancías y, al mismo tiempo, puntos de confluencia de las fuerzas culturales globales y locales. Para que sirvan como fundamentos a esta reflexión, también establece marcos de referencia de la cultura japonesa y del crecimiento del deporte en Japón. Se concluye que a pesar de la fuerte influencia ejercida por símbolos de la identidad japonesa, la representación del deporte en los animes y mangas se está acercando cada vez más a la (post)modernidad occidental, debido a la globalización y a la transnacionalización de bienes inmateriales.
*Universidade Federal do Oeste do Pará. Santarém, PA, Brasil. E-mail: gilsu05@gmail.com

Recebido em: 02-02-2017 Aprovado em: 25-05-2017

\section{(c) (1) (8) Licence}




\section{INTRODUÇÃO}

Na contemporaneidade, o esporte detém crescente importância econômica, política e cultural. Trata-se de um fenômeno que se espraia por diversas manifestações que não têm se restringido à esfera da prática em primeira mão, estendendo-se para uma série de novas e antigas formas de engajamento e consumo mediadas por imagens ${ }^{1}$. Nesse sentido, além dos veículos de informação que exploram suas facetas factuais, como a transmissão de competições e notícias, o esporte também se vê retratado em modos de expressão que acionam suas dimensões ficcionais e simbólicas. Nas últimas décadas, o cinema, a literatura, as telenovelas e séries de TV têm servido como grandes zonas de visibilidade nas quais 0 universo esportivo exerce a sua função contemplativa.

Em outro viés, também são cada vez mais numerosas as formas midiáticas alternativas de fruição do esporte, dentre as quais ao menos duas merecem destaque: os mangás e animes². Diante de sua disseminação planetária, ambos têm se afirmado como objetos de interesse acadêmico. Nesse contexto, o presente ensaio pretende discutir as inserções do esporte no fenômeno dos mangás e animes. Para isso, propõe-se a enfrentar três aspectos caros à fundamentação, contextualização e ao desenvolvimento do debate, a saber: 1) a cultura japonesa na era global; 2) elementos históricos e sociais da ascensão do esporte no Japão; 3 ) papéis e manifestações do esporte na cultura dos mangás e animes.

\section{FENÔMENO DA CULTURA JAPONESA: A ASCENSÃO DOS ANIMES E MANGÁS}

$\mathrm{Na}$ atualidade, o Japão é um território que tem recebido bastante atenção do mundo ocidental. No âmbito acadêmico, sua cultura, história e tradições vêm despertando o interesse de inúmeras disciplinas e áreas do conhecimento. Sugimoto (2009) explica que tais estudos vêm passando por uma série de transformações profundas. Com o gradativo reconhecimento das singularidades de seu cotidiano, o Japão vem se afastando da imagem de sociedade monocultural e homogênea, assumindo a sua constituição multiétnica e estratificada que, por sua vez, expõe assimetrias regionais (campo-cidade), geracionais (jovens-adultos-idosos), socioeconômicas (ricos-pobres) e baseadas em gênero (homens-mulheres). Contudo, sob a ótica identitária, esse conjunto de tensões encarna desafios que são usualmente administrados como questões a serem resolvidas internamente pelo país e que, portanto, não geram impactos significativos sobre a imagem deste perante o restante do mundo.

Entre os enfoques emergentes nesse campo, estão aqueles que interpelam direta ou indiretamente as forças do mercado, as quais exercem influência significativa na forja da cultura japonesa contemporânea. Desde a segunda metade do século $X X$, o Japão vem deixando de sustentar sua economia na produção em larga escala de bens materiais de baixo custo para consumo massivo, redirecionando seu foco para a fabricação e comercialização de bens culturais cuja disseminação pode ser sentida tanto em âmbito local quanto internacionalmente. Nesse caso, o que circula não são apenas mercadorias feitas no e para o país, mas também um conjunto de imagens do próprio que não raro fornecem versões sinedóquicas dos modos de vida e pensamento característicos do Japão.

1 Para um panorama geral das investigações sobre a unidade esporte-mídia, ver Santos et al. (2014). 
Em geral, tais produtos têm naturezas e lógicas de produção distintas. De acordo com Sugimoto (2011), os principais bens culturais atualmente exportados pelos japoneses se dividem em três categorias distintas, mas congruentes: 1) símbolos pré-modernos: folhas de cerejeiras, o "espírito" samurai, gueixas, shamisen", monte Fuji e demais entidades que predominam desde a Segunda Guerra Mundial; 2) representações da lógica corporativa japonesa: controles de qualidade, métodos de ensino e outros produtos imbuídos do suposto e controverso espírito workaholic do trabalhador médio do Japão; e 3) imagens "não japonesas", categoria que se popularizou durante a década de 1990 graças a romances de escritores mundialmente premiados como Haruki Murakami (2012) e Banana Yoshimoto (1988), cujas histórias são ambientadas em quaisquer tempos e contextos de difícil associação a atributos (ou estereótipos) reconhecidamente japoneses. Em termos de mercado, essas commodities ocupam o mesmo patamar das mercadorias físicas convencionais, como carros e aparelhos eletrônicos. Tais produtos

[...] estão se tornando cada vez mais visíveis ao redor do planeta, variando de animes, mangás, karaokê, sushi, moda e artes marciais. É o mesmo caso das mercadorias-conhecimento como jogos sudoku, métodos de instrução Kumon e os métodos Suzuki de ensino da música [...] Enquanto o estado tenta se estabelecer como um "poder suave" no mundo, o capitalismo japonês encontra seu maior mercado nos chamados produtos 'cool do país (SUGIMOTO, 2011, p.14, tradução minha).

Nessa conjuntura, os mangás e animes atuam na vanguarda de uma onda "japanofílica" planetária. Resumidamente, podemos defini-los, respectivamente, como histórias em quadrinhos e animações em estilo japonês. Ambos representam formas expressivas distintas, mas que costumam estar intimamente ligadas entre si e com as demais ramificações das indústrias culturais da região - a exemplo dos games, doramas ${ }^{4}$, j-music e live-actions ${ }^{5}$. Sob o ponto de vista criativo, boa parte dos animes e demais ficções televisivas são adaptações de mangás de sucesso, os quais representam, no cenário atual, não apenas um nicho dominado por mangakas ${ }^{6}$ profissionais, mas também um ramo constituído por incontáveis artistas amadores que criam e divulgam seus trabalhos sob a forma de doujinshis ${ }^{7}$, sem o respaldo de editoras ou quaisquer tipos de mecenas.

Apesar de não existirem informações precisas acerca do exato momento em que surgiram os mangás, sabe-se que a sua popularização está intimamente ligada à história recente do Japão. Até a primeira metade do século XX, o país se constituiu como um cenário imerso em extrema pobreza. $O$ atual panorama de prosperidade e desenvolvimento só começou a se desenhar após o trágico desfecho da Segunda Guerra Mundial, quando o Japão, diante dos traumas e da destruição resultantes do confronto, implementou diversas macromudanças que aceleraram o seu processo de modernização.

De acordo com Luyten (2009), a participação dos EUA, então adversário do Japão na Segunda Guerra, foi decisiva no processo de recuperação do país. Com o avanço de regimes comunistas por todo o planeta, fortalecer o Japão se tornou uma demanda estratégica para

\footnotetext{
3 Instrumento de cordas típico do Japão feudal, o qual é utilizado na execução de músicas pertencentes a gêneros tradicionais como o Sankyoku.

4 Nome dado às séries de televisão orientais.

5 Adaptações de histórias de mangás e animes feitas com atores reais.

6 Alcunha que recebem os cartunistas e quadrinistas japoneses.

7 Produções independentes que correspondem a versões nipônicas dos fanzines.
} 
os norte-americanos. Sob a ótica das Forças Aliadas, os japoneses, uma vez reestruturados, poderiam "retribuir" o auxílio recebido na revitalização do país por intermédio da resistência frente à ideologia e aos estados do eixo soviético, agindo como uma espécie de vetor de proteção dos interesses capitalistas ianques no contexto asiático. Trata-se de um movimento que aglutinou uma série de transformações estruturantes e cuja pedra angular foi a exitosa reforma agrária que promoveu uma redistribuição igualitária de terras à população, que na época se encontrava em acentuado estado de penúria, enfraquecendo assim antigas oligarquias latifundiárias e atenuando problemas crônicos, como a fome e o desemprego.

No transcurso dessa reconstrução, os mangás despontaram como uma forma de lazer compatível com os limitados recursos do país. Até os dias de hoje, as histórias retratadas em suas dezenas ou mesmo centenas de páginas servem como distração barata, descartável e catártica aos japoneses (LUYTEN, 2009, p. 19) - características que também se estendem aos animes.

Considerados estandartes da cultura visual asiática, os animes e mangás são portadores de algumas ambivalências aparentemente insolúveis. Como vimos, a economia japonesa tem direcionado boa parte de seus investimentos às mercadorias capazes de transcender necessidades e interesses exclusivos do país, e que por isso apresentam plenas condições de consumo em quaisquer coordenadas do globo. Ainda assim, se há consenso de que tais características se aplicam aos mangás e animes, também é pouco questionado 0 entendimento de que 0 interesse externo em tais produtos advém igualmente da aura de exotismo que exalam e que é ainda mais nítida aos indivíduos ocidentais. Ou seja, o seu apelo reside no fato de não serem "japoneses demais" a ponto de se tornarem herméticos ao paladar estrangeiro, mas ao mesmo tempo por serem "japoneses o suficiente" a ponto de ostentarem um valor simbólico explícito.

O apelo à niponicidade dos mangás e animes é bastante compatível com os desígnios do nacionalismo cultural. Estes podem ser mais facilmente entendidos quando contextualizados no processo de globalização, que, na ótica de Inoguchi (2009),

[...] é multidimensional. Ela envolve uma gama de fenômenos que contribuem para a confluência desigual da diferença local [...] 0 nacionalismo cultural não é menos importante nos debates em torno do valor da globalização. Uma vez que muitos aspectos da vida humana são progressivamente - e com frequência irreversivelmente - globalizados, um após outro, o nacionalismo cultural pode se tornar o último bastião de protesto contra a globalização. 0 nacionalismo cultural envolve 0 anseio por uma comunidade imaginada. Trata-se da coesão e da solidariedade em termos de memórias e arquiteturas compartilhadas daquilo que constitui o destino autodefinido de um povo, aspectos estes que normalmente se contrapõem às forças globalizantes que comprometem um modo de vida atual. Da mesma forma que teve início a partir da construção de comunidades imaginadas, o estado-nação deve defender-se através da subscrição convicta de seus cidadãos à manutenção de tais abstrações. Quando as bases materiais do estadonação parecem ser minadas dia a dia pela globalização, as bases ideacionais e emocionais de sua existência devem ser defendidas a qualquer custo. Nesse sentido, o nacionalismo cultural é uma força defensiva em seu objetivo, mas agressiva em sua manifestação (INOGUCHI, 2009, p. 339, tradução minha).

$\mathrm{Na}$ contemporaneidade, a distribuição de mangás e animes vem passando por transformações sensíveis. Até o fim da década de 1990, o acesso a esse tipo de conteúdo se manteve subordinado ao interesse e empenho de editoras e emissoras de TV. A partir dos 
anos 2000, este leque de possibilidades se viu ampliado não somente graças à multiplicação dos canais de TV por assinatura, mas também pela generalização da rede mundial de computadores, fato que tornou possível o surgimento de serviços de distribuição de conteúdo via streaming, a exemplo de iniciativas como o Crunchyroll?.

A popularização da comunicação via internet também dilatou esse campo de possibilidades de consumo mediante a afirmação de uma série de mecanismos de difusão informais que nem sempre operam em conformidade com as leis de direitos autorais e propriedade intelectual. Nesse caso, vale destacar o protagonismo de agentes como os scanlators (usuários que digitalizam, traduzem e disponibilizam gratuitamente mangás) e os fansubers (voluntários que digitalizam, legendam e sincronizam os animes). A despeito de suas singularidades, todos esses veículos contribuem com o aumento da assimilação mundial da cultura visual japonesa impressa e audiovisual, tornando também mais intensa a dispersão de perspectivas nipocêntricas sobre temas e acontecimentos cada vez mais variados, entre os quais figuram aqueles que dizem respeito ao esporte.

\section{ENTRE 0 OCIDENTE E O ORIENTE: O ESPORTE, OS MANGÁS E OS ANIMES}

Atualmente, o esporte pode ser considerado um fenômeno cuja gênese é amplamente debatida em diferentes ramos das Ciências Humanas. Ao reunir as principais perspectivas sociológicas sobre o tema, Bracht (2003) define o esporte moderno como "uma atividade corporal de movimento com um caráter competitivo surgida no âmbito da cultura europeia do século XVII, e que com esta, expandiu-se pelo resto do mundo" (p. 13). Mais do que isso, também o compreende como uma força capaz de fagocitar outros elementos da cultura corporal, alinhando-os a princípios como: competição, rendimento físico-técnico, busca pelo recorde, racionalização e cientifização do treinamento. Esse foi o destino dos jogos populares praticados pela classe trabalhadora inglesa, os quais entraram em declínio no final do século XVIII por conta da intensificação de processos como a urbanização e a industrialização ${ }^{9}$.

Diante disso, como falar do esporte no contexto oriental, cenário composto por inúmeros territórios heterogêneos onde tais esquemas explicativos parecem não se aplicar com a mesma eficácia? No Japão, a modernidade que fez nascer a expressão hegemônica do esporte contemporâneo só deu seus primeiros passos em 1868, com a Revolução Meiji: acontecimento que pôs fim ao sistema feudal e ao regime teocrático-imperial que durante séculos vigoraram no país. Durante o Período Meiji (1868-1912), o Japão iniciou um conjunto de reformas que reestruturou seus sistemas políticos, econômicos e educacionais, adquirindo as primeiras feições de um estado-nação, além de forçar uma abertura formal não só aos países vizinhos, mas também a todo o eixo ocidental.

O exato lugar do esporte na modernização japonesa ainda é um debate repleto de indefinições. $O$ que se pode afirmar é que este cumpriu tanto o papel de objeto afetado pelo referido processo, quanto o de seu veículo fomentador. Koishihara (2009) define o esporte como uma espécie de fusão entre formas modernas e tradicionais de exercício físico instaladas na cultura japonesa e que também atuaram como forças reguladoras da entrada e circulação de culturas estrangeiras no âmago dos modos de vida nipônicos. Até o início do Período Meiji,

8 Mais detalhes em: $h$ ttp: $: /$ www.crunchyroll.com/

9 Frente à complexidade do debate, a problemática do esporte moderno não será aprofundada aqui. Para maiores detalhes a respeito, ver Bracht (2003) e Martins (2007). 
as atividades corporais do Japão tradicional tinham como principal lastro 0 alinhamento entre os rituais religiosos xintoístas ${ }^{10}$ e 0 código de conduta dos samurais - também chamado de Bushido ("caminho do guerreiro"). Destituindo tais motes de sua centralidade milenar, o contato com o mundo ocidental acelerou a sistematização e racionalização de práticas ancestrais, como a luta sumô, o kyusha ${ }^{11}$, kenjutsu ${ }^{12}$ e 0 jujutsu ${ }^{13}$, fazendo com que estas se ajustassem a sistemas de regras passíveis de serem institucionalizados de modo a viabilizar a criação de métodos objetivos de treinamento, bem como a organização de certames em quaisquer lugares do globo. Em contrapartida, várias das modalidades advindas de outros países também foram alinhadas à cultura e aos princípios japoneses. Um dos exemplos é o tênis, que, ao chegar ao país, teve sua estrutura básica sutilmente alterada, tornando-se soft tennis: uma prática quase idêntica à original, mas que se distingue apenas pelo uso de raquetes mais leves e de bolas de borracha. Trata-se de uma adaptação forçada pela escassez material que se agravou no país durante os anos de guerra.

Se o esporte representa um ponto de convergência entre a ancestralidade asiática e a modernidade europeia, pode-se dizer que a Educação Física agiu (e ainda age) como importante intercessor entre os referidos polos no contexto do Japão. Koishihara (2009) descreve algumas evidências da íntima articulação entre as instituições escolares, o esporte e a cultura japonesa:

Em 1878, George A. Leland, um pensador americano da Educação Física, foi convidado para o Japão como professor no recém-fundado Taisō-Denshujo (Instituto Nacional de Ginástica). Foi a primeira escola de formação de professores de Educação Física escolar financiada pelo governo. Esta introduziu metodologias de ensino e teorias modernas da Educação Física, adotando tanto exercícios livres quanto exercícios que envolvem o uso de aparelhos e equipamentos de mão da 'ginástica normal'. Mais tarde, a 'ginástica militar' foi introduzida à Educação Física escolar como um componente obrigatório. Esses exercícios físicos faziam parte de um programa de treinamento de estilo ocidental adotado pelo exército japonês em consonância com a prosperidade nacional e a política de defesa. Para fornecer espaço à prática destes exercícios, as escolas começaram a construir playgrounds planos com cerca de 6600 a 10000 metros quadrados de tamanho. Este terreno também foi utilizado como espaço para a prática de beisebol, atletismo e outras atividades esportivas importadas e para a realização de competições. A prática de exercícios de ginástica e esportes tradicionais ocidentais alterou o tradicional modo de andar japonês. Essa mudança também transformou a indumentária da população: do tradicional traje japonês às roupas ocidentais - que são mais adequadas à prática de atividades físicas. Apesar da forte resistência à introdução de esportes estrangeiros com elementos de jogo e entretenimento, vinda principalmente de pessoas da antiga classe samurai, essas práticas continuaram sendo absorvidas, resultando em mudanças visíveis e significativas no modo de se movimentar dos japoneses (KOISHIHARA, 2009, p. 326, tradução minha).

Repleto de conflitos, imposições e resistências, o devir das relações entre esporte e cultura produziu uma série de macrotendências no âmbito dos mangás e animes. A primeira é de ordem temática e diz respeito à conexão entre as modalidades mais recorrentes nas histórias e aquelas que estão mais presentes no cotidiano japonês, tais como o futebol, o soft tennis, o basquete, o vôlei e o badminton (KOISHIHARA, 2009, p. 318). No topo dessa lista

10 Mais detalhes em Covell (2009).

11 Uma espécie de tiro com arco realizado em cerimônias especiais. 
está aquele que é considerado o esporte nacional do Japão: o beisebol. Dele veio a inspiração para o primeiro mangá serializado do gênero ${ }^{14}$ : Star of The Giants. Lançado no ano de 1966, seu enredo gira em torno de Hyuma Hoshi, um jovem e promissor lançador que sonha em se tornar uma estrela da Liga Profissional Japonesa como seu pai, Ittetsu Hoshi (FIGURA 1). Este, após se destacar como homem da terceira base, foi obrigado a se aposentar precocemente por conta de uma sequela decorrente de um ferimento sofrido na Segunda Guerra Mundial. Após transformar-se em anime em 1967, Star of the Giants abriu caminho para muitas outras séries de sucesso sobre beisebol, tais como Major (2004), Ookiku Furikabutte (2007), Moshidora (2011) e Diamond no Ace (2013).

Figura 1 - Star of the Giants: à esquerda, mangá e, à direita, anime

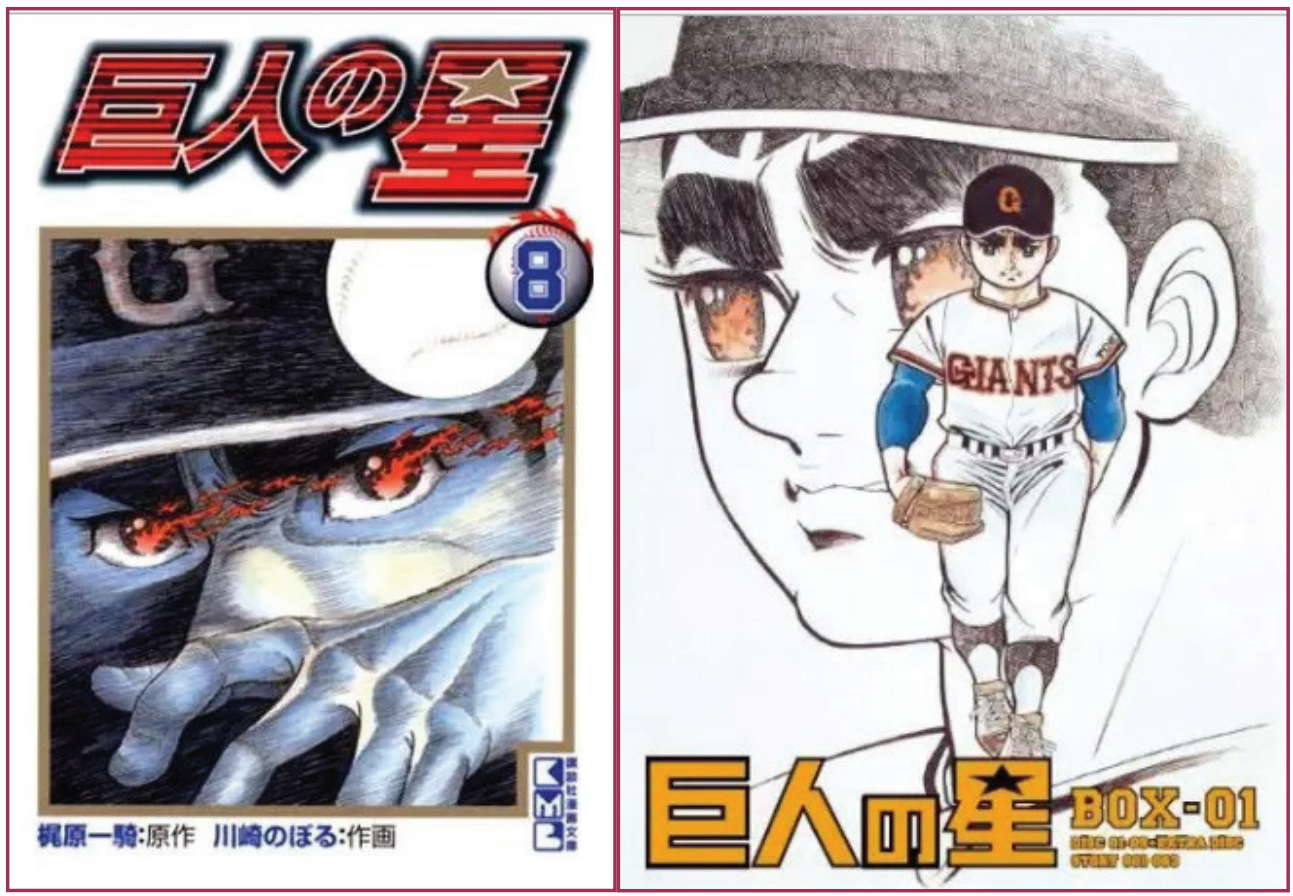

Fonte: My Anime List: <https://myanimelist.net/anime/5834/Kyojin_no_Hoshi>.

Parece oportuno que o primeiro mangá esportivo tenha nascido apenas dois anos depois daquele que é considerado um dos acontecimentos mais relevantes na história recente do Japão: os Jogos Olímpicos de Tóquio em 1964. Trata-se da primeira edição do evento realizada na Ásia e que, para além do valor simbólico intrínseco à celebração, teve inegável importância política para o país-sede. Após anos de pobreza, guerras e, finalmente, reconstrução, era chegada a hora de apresentar ao mundo o até então desconhecido "milagre econômico japonês", dádiva para a qual poucas vitrines seriam tão convenientes quanto os Jogos Olímpicos: megaevento que reúne num único território fração significativa das nações do mundo.

Mais do que isso, esse acontecimento selou em definitivo a aliança entre o esporte moderno e os grandes meios de comunicação no Japão. Ao serem transmitidas pela TV, as competições se tornaram acessíveis a torcedores, entusiastas de modalidades variadas ou mesmo indivíduos sem quaisquer vínculos prévios com o esporte. Em certa medida, esse gesto

14 Nesse caso, são desconsiderados os mangás publicados na forma de tiras avulsas publicadas jornais e demais veículos de comunicação impressa (NORRIS, 2009). 
ajudou a sensibilizar os japoneses para modos emergentes de consumo e fruição do esporte, abrindo caminhos para veículos de informação, juntamente com outras formas de expressão e entretenimento em processo de afirmação, como os próprios animes e mangás.

Outro aspecto digno de destaque diz respeito ao modo de classificação dos mangás e animes. Nesse sentido, há uma apropriação de várias das etiquetas presentes nos gêneros literários e fílmicos do ocidente, tais como: comédia, terror, romance, suspense, ficção científica e, obviamente, esporte. No contexto japonês, a última é frequentemente nomeada de spokon, combinação do vocábulo inglês "sport" com a palavra japonesa "kōnjo", cujo significado se aproxima à ideia de "coragem". A despeito de seu caráter supostamente autoexplicativo, esses e outros rótulos inscritos nesse sistema classificatório são pouco eficazes para transmitir uma visão geral das histórias quando aplicados isoladamente. Por isso, parece mais apropriado considerar os gêneros como palavras-chave flexíveis e intercambiáveis do que como estruturas temáticas rígidas e monolíticas. Isso significa que tais termos têm seu potencial de categorização subordinado aos arranjos e às articulações entre dois ou mais conceitos distintos.

O universo dos animes e mangás tem seu próprio conjunto exclusivo de gêneros, no interior do qual destacam-se os recortes de ordem demográfica. Buscando atingir públicos específicos, estes costumam se configurar de acordo com especificidades de idade e sexo dos leitores e espectadores pretendidos. Entre as categorias mais conhecidas, quatro são dignas de menção:

- Shōnen: voltadas a crianças e adolescentes do sexo masculino, essas histórias se popularizaram na década de 1960 e tendem a apresentar enredos que equilibram ação, disputas e humor, revestidos pelo espírito de camaradagem e pela cooperação entre pares, sendo quase sempre protagonizados por homens;

- Shōjo: equivalente feminina dos mangás Shōnen, essa vertente ascendeu nos anos de 1970, apresentando elementos de comédia e luta, distinguindo-se por seu enfoque em dramas, romances e narrativas com maior carga emocional, além de ter imortalizado as icônicas personagens com olhos grandes e expressivos - traço considerado identitário dessa forma artística;

- Seinen: dirigida a jovens-adultos do sexo masculino, essa categoria lida com linguagens e temas mais maduros, como sexo, violência e críticas sociais;

- Josei: equivalente feminina dos mangás Seinen, aborda assuntos extraídos do cotidiano de mulheres adultas, operando de modo menos idealizado e caricato que as estórias Shōjo.

Além de ser o segmento mais popular no Japão, o gênero shōnen atualmente é um dos maiores aliados dos mangás e animes de esporte. Trata-se do nicho que reúne séries emblemáticas como Saint Seyia(1986), Dragon Ball(1984) e Naruto (1999), as quais alcançaram sucesso mundial, inclusive no Brasil, onde esses e tantos outros títulos similares foram ou ainda são exibidos em canais de TV aberta e por assinatura. Não obstante, sua articulação com o esporte não se deve apenas ao seu crescente público consumidor e potencial de adesão. Narrativas shōnen também se caracterizam como um campo extremamente favorável à operacionalização de princípios intrínsecos ao esporte moderno e às suas representações no âmbito do entretenimento. Isso fica explícito em séries que retratam esportes ficcionais, mas que normalmente nem sequer são enquadradas como spokon's, a exemplo de Pokémon (1997), Yu-Gi-Oh (1996) e Beyblade (2000): por intermédio de monstros, cartas ou peões, respectivamente, os personagens principais dessas histórias estão constantemente competindo 
informal e formalmente, buscando melhorar seu desempenho através do treinamento e com isso superar marcas objetivas (recordes e campeonatos) ou subjetivas (adversários e inimigos). $\mathrm{Na}$ atualidade, a estrutura das histórias shōnen é bastante similar aos padrões narrativos observados nos romances de formação (bildungsroman), gênero literário surgido na Alemanha do século XVIII e cujo objetivo é descrever com detalhes o processo de desenvolvimento físico, moral, intelectual e afetivo de um determinado personagem ao longo de sua vida, levando em consideração seus principais percalços e conquistas (INGULSRUD; ALLEN, 2009, p. 10).

A centralidade em atividades com inspiração esportiva é uma das táticas comerciais mais difundidas no ramo dos animes e mangás, sobretudo aqueles que são dirigidos ao público infantojuvenil. Em meio à multiplicação das narrativas transmidiáticas, intensifica-se a irradiação de universos ficcionais singulares por intermédio de plataformas midiáticas diversificadas (JENKINS, 2009). Os animes e mangás são objetos de troca e desejo que circulam num amplo mercado transnacional de bens simbólicos, nos quais atuam múltiplas indústrias culturais (cinema, literatura, televisão) com as quais tais produtos podem se conectar por intermédio de suas histórias, cenários e personagens. Por serem atividades baseadas em sistemas de regras que engajam seus participantes através da comparação de performances individuais e coletivas, os esportes podem ser facilmente absorvidos pelas culturas lúdicas de leitores e espectadores, haja vista sua elevada capacidade de integração às commodities utilizadas em jogos e brincadeiras, como é o caso de brinquedos e videogames.

Mouer e Norris (2009) explicam que, durante o período pós-guerra, a cultura (visual) japonesa sofreu forte interferência dos grandes estúdios hollywoodianos. Na época da ocupação estadunidense no Japão, eram muito populares os quadrinhos e desenhos animados com assinaturas mundialmente conhecidas, tais como aquelas pertencentes à Walt Disney que, por sua vez, exerceu inegável influência sobre a composição estética dos animes e mangás. Essas referências também permearam o substrato moral das referidas narrativas, expressando-se mediante personagens icônicos como Astroboy, que "[...] deram nova vida às noções americanas de organização social, trabalho em equipe e cultura corporativa, derivadas dos manuais das forças armadas dos EUA" (p. 367, tradução minha).

Uma compreensão ampliada do esporte nos animes e mangás também demanda a capacidade de discernir conteúdos e comportamentos manifestos de seus respectivos ethos subjacentes. Mesmo eivados de influências ocidentais, os enredos dos animes e mangás ainda se mantêm fiéis a algumas bases deontológicas da cultura local e nacional. Lançado em 2008, o mangá Kuroko no Basket conta a história de Kuroko Tetsuya, um estudante do ensino médio que, apesar de fraco e incapaz de driblar e arremessar, foi o integrante "invisível" de uma equipe de basquete altamente vitoriosa em competições escolares do Japão. Quando o referido time se desfez, dispersando seus membros por diferentes escolas, Kuroko decide ir para a Seirin High School, uma instituição sem qualquer tradição na modalidade e onde pôde conhecer Kagami Taiga: um jovem vindo dos EUA que, apesar da personalidade difícil, apresenta um talento notável para o basquete. A despeito da presença de clichês correntes nas ficções concernidas no esporte, tal como o jargão do "vira-latas 15", Kuroko no Basket é repleto de simbolismos que dão pistas de seu espírito nipônico. Uma dessas conexões é a dualidade existente entre a individualidade excepcional de Kagami e a postura integradora de Kuroko: nas quadras, apesar dos pontos decisivos marcados pelo primeiro, é o segundo quem garante a coesão da equipe 
e a plena manifestação das destrezas de cada um, seja através de assistências precisas, seja mediante falas eloquentes e insights motivacionais (FIGURA 2). Vale lembrar que, mesmo diante do destaque dado à figura de Kagami, Kuroko é quem ocupa (discretamente) o centro da história, podendo ser considerado como uma personificação da visão de mundo holística presente em boa parte das culturas orientais: as partes em plena e perpétua harmonia com 0 sistema (o todo). Em muitas situações, isso se reflete num entendimento comunitário acerca da subjetividade: "Mais do que focar em jogadores e heróis individuais, a escola que cada time representa assume o status de personagem" (INGULSRUD; ALLEN, 2009, p. 10, tradução minha). Nesse raciocínio, o verdadeiro protagonista de Kuroko no Basket seria, portanto, a equipe de Seirin High e não Kuroko ou Kagami.

Figura 2 - Kuroko no Basket ${ }^{16}$

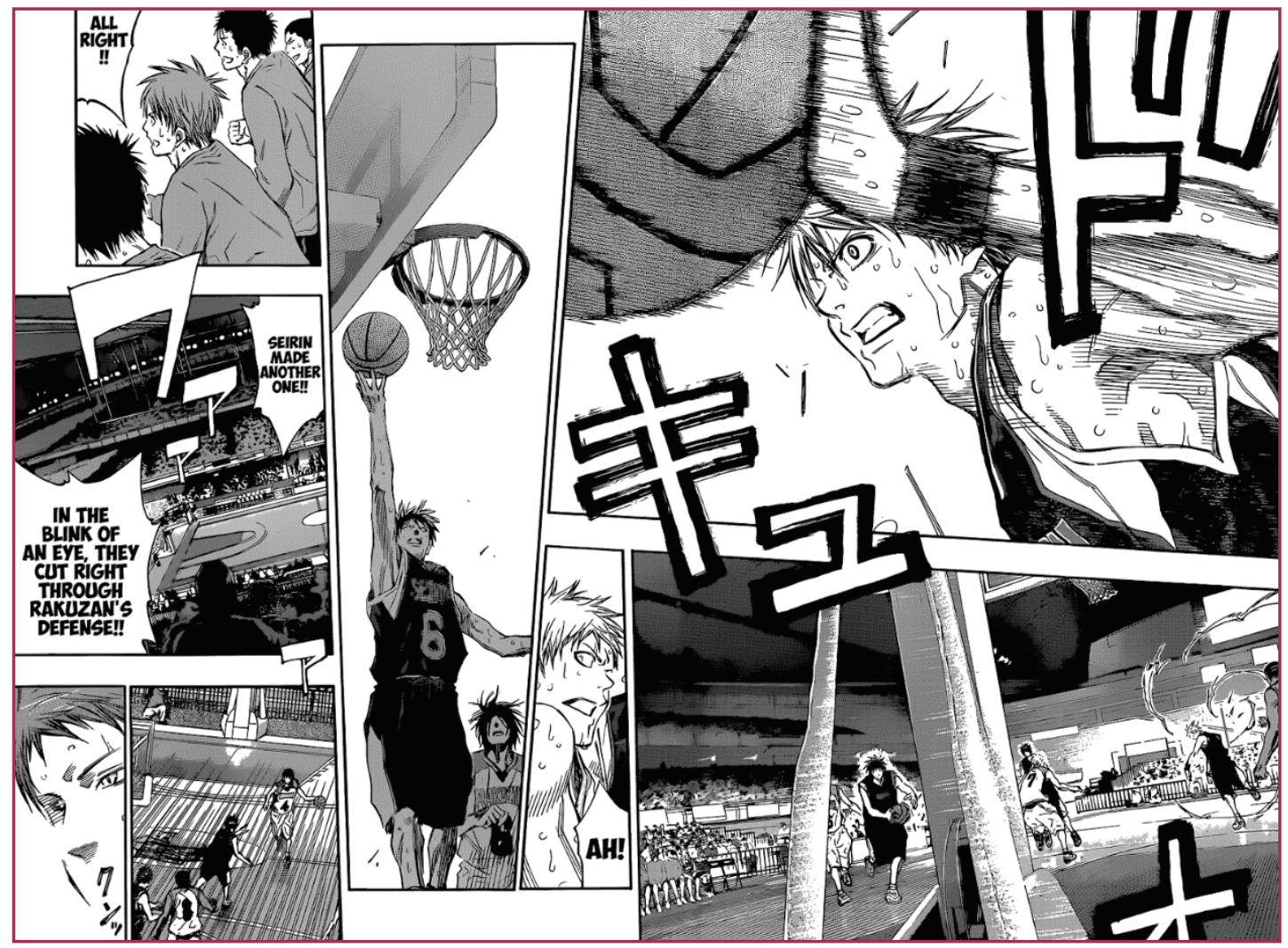

Fonte: Acervo do autor.

No Japão, a sobreposição do indivíduo aos desígnios da coletividade não costuma ser um traço digno de admiração. Muito pelo contrário, uma vez que se trata de:

[...] um país onde, desde cedo, se ensina às pessoas que, quando um prego se sobressai no tabuleiro, é preciso bater-lhe à cabeça. O grande martelo é a sociedade que se encarrega de muitas maneiras - seja pelo controle ou seja pela imposição de rígidas regras sociais - de nivelar a cabeça dos que tentam sobressair-se. 0 individualismo não é bem visto. É considerado uma forma de egoísmo, e, portanto, o pagamento pelo bem-estar social é a perda da individualidade. Desse modo, 0 herói japonês é alguém que levanta a cabeça, mas não para perturbar a ordem social (LUYTEN, 2011, p. 55).

Os animes e mangás também parecem estar sujeitos a tendências emergentes mais amplas no âmbito das representações do esporte na contemporaneidade. Para Araújo (2012),

16 Fonte: <http://www.kurokonobasketmanga.com/2014/03/kuroko-no-basket-manga-chapter-252.html>. 
a crise da modernidade tem gerado uma série de fissuras na concepção de esporte que ascendeu no fim do século XIX para o início do século XX, a mesma que atualmente representa sua forma hegemônica. Tomando como referência o cinema e em diálogo com a noção de pós-modernidade, o autor descreve alguns indícios do gradual afastamento da expressão do esporte contemporâneo de cânones modernos, como a competição, o rendimento e o recorde, os quais vêm cedendo lugar a uma miscelânea de novos motes em ascensão, tais como consumo, cultura pop, gênero e sexualidade.

Lançado em 2016, o anime Yuri!!! on Ice pode ser considerado um dos prenúncios da pós-modernidade na cultura visual japonesa (FIGURA 3). Essa história tem como protagonista Yuri Katsuki, um jovem e promissor patinador artístico que, após sofrer uma traumática derrota no campeonato mundial da modalidade, decide se afastar das competições e se dedicar aos estudos em uma universidade de Detroit. Cinco anos depois de sua última competição, Yuri decide retornar à sua cidade natal no Japão e, uma vez lá, visitar sua amiga de infância, Yuko, com a qual se encontra num rinque de patinação. Sem saber que estava sendo gravado, Yuri reproduz com perfeição a coreografia de um dos mais consagrados patinadores da história e ídolo do protagonista: o russo Victor Nikiforov. Depois que seu vídeo foi parar na internet, viralizando sua performance, Yuri recebe em sua casa a visita surpresa de Victor, que se oferece para ser seu treinador e ajudá-lo a conquistar o campeonato mundial de patinação artística.

Figura 3 - Yuri!!! On Ice

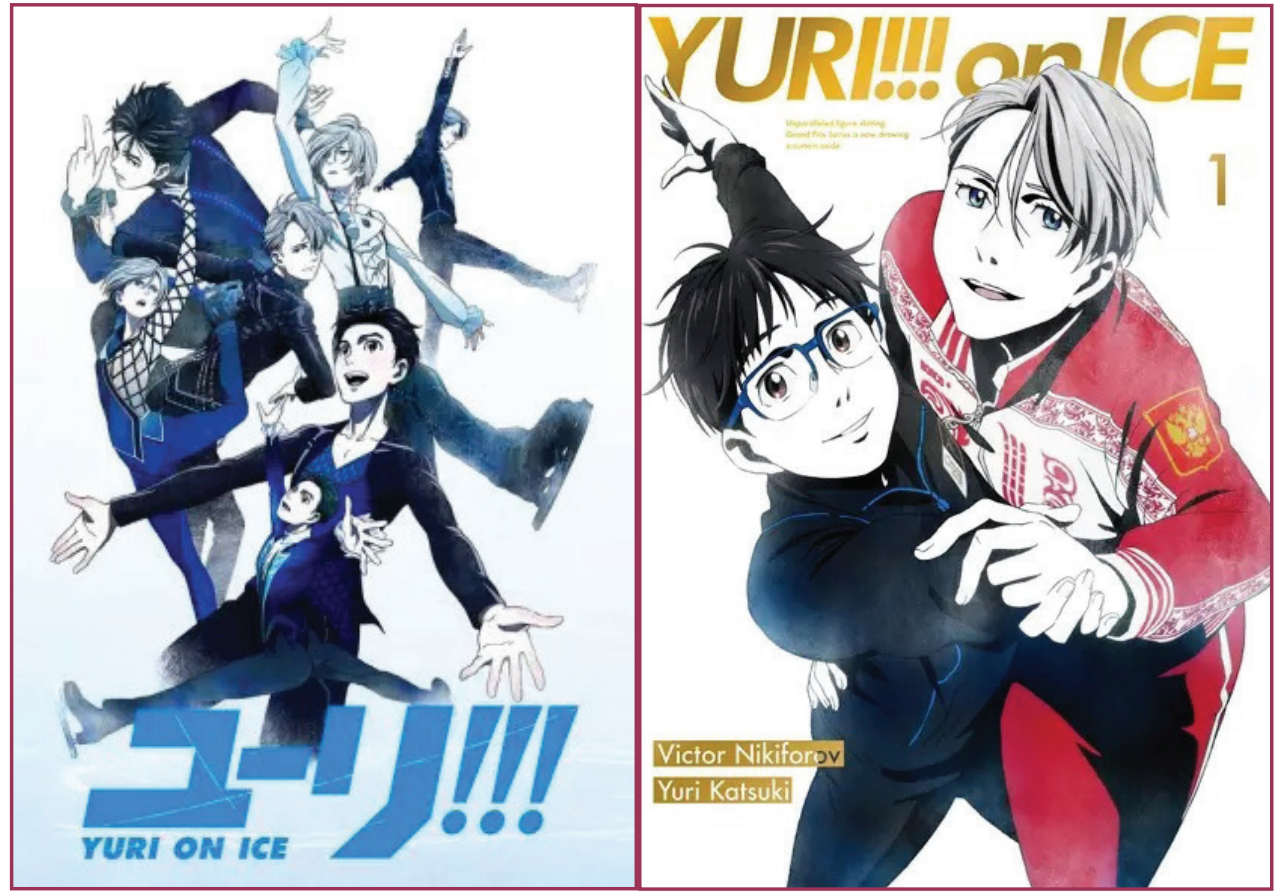

Fonte: My Anime List: <https://myanimelist.net/anime/32995/Yuri_on_ICE?q=Yuri!!!>

A boa recepção de Yuri!!! On Ice pode ser vista como um sintoma do enfraquecimento dos arquétipos dramáticos kitsch que alimentam a maior parcela dos títulos de grande circulação, a exemplo das séries shōnen e shōjo. Primeiramente, a crítica especializada teceu elogios à qualidade da animação, cuja estética conseguiu retratar com elegância e leveza os gestos e o universo particular da patinação artística ${ }^{17}$. Por outro lado, a escassez de detalhes 
relativos a aspectos técnicos típicos da modalidade foi considerada um ponto fraco do anime ${ }^{18}$, "deslize" este que também pode ser interpretado como a perda de centralidade dos preceitos modernos no cerne das narrativas ligadas ao esporte, tais como a já referida ênfase no knowhow e no esforço balizado pela disciplina como meio único para alcançar o triunfo.

A despeito do flerte com os lugares-comuns conjurados regularmente nos enredos spokon, tal como o chavão do atleta fracassado em busca de redenção ${ }^{19}$, Yuri!!! on Ice não destoa apenas por eleger uma modalidade periférica nas ficções ligadas ao esporte. Ao ostentar personagens do sexo masculino engajados numa atividade ordinariamente associada a atributos "femininos", a série pôde criar disjunções entre o imaginário social acerca da patinação e visões estereotípicas de gênero, abrindo caminho para a evocação de tópicos caros a grupos sociais não hegemônicos, sobretudo às comunidades queer ${ }^{20}$. Além disso, 0 anime também mostra o desenvolvimento de uma relação de afeto e parceria entre Yuri e Victor que extrapola a admiração entre atleta e treinador/ídolo. Ironicamente, relações homoafetivas são consideradas tabu nos países de origem de ambos os protagonistas (Japão e Rússia), contextos em que ainda não é permitida a união estável entre pessoas do mesmo sexo, mas onde também é intensa a reivindicação de direitos por parte dos segmentos LGBT. Não se sabe ao certo se essa dissonância ocorre por causa de pressões externas exercidas por forças globalizantes ou pelas fissuras geradas por dissidências culturais intrínsecas ao próprio Japão. O que se pode afirmar é que tais observações sugerem que os animes e mangás não devem ser vistos como meros veículos de propaganda a serviço de uma niponicidade oficial - e, portanto, imaginada -, uma vez que esta está sempre sujeita à transformação, negociação ou mesmo rejeição (NORRIS, 2010).

\section{CONSIDERAÇÕES FINAIS}

Atualmente, animes e mangás são pedras angulares da cultura visual asiática, cujo processo de transnacionalização impregna personagens, cenários e modos de vida com os sincretismos entre tradição, modernidade e, mais recentemente, pós-modernidade. Se nas manifestações do esporte dessas narrativas têm prevalecido imagens e princípios tipicamente modernos, traço que revela sua proximidade com a cultura (de massa) ocidental, também é razoável acreditar numa pluralização desse mosaico no sentido de um fortalecimento de temáticas e perspectivas periféricas, as quais vêm adquirindo cada vez mais representatividade tanto no bojo das lutas culturais, quanto na configuração e no exercício de "poderes suaves".

Frente à força e ubiquidade da globalização, também são oportunas indagações como: o que ainda resta de genuinamente "japonês" na cultura japonesa? Se ainda existe uma identidade nacional nipônica supostamente imaculada, em que medida ela influencia os processos de criação e circulação dos animes e mangás com temática esportiva? Quais tipos de hibridação entre o local e o global essa indústria tem propiciado através de sua política de representação do esporte? Como ocorrem os processos de recepção e consumo cultural de tais conteúdos em regiões específicas do planeta?

Por fim, este ensaio não teve como objetivo revelar todas as nuances da problemática envolvendo as conexões entre o esporte e os animes e mangás. Trata-se de um campo

18 Fonte: <http://site.animeuknews.info/2016/11/24/streaming-review-of-yuri-on-ice-episodes-1-8-crunchyroll/>

19 Mais detalhes em: <http://tvtropes.org/pmwiki/pmwiki.php/Main/RedemptionQuest>.

20 Mais detalhes em: <http://kotaku.com/why-people-are-hyped-about-a-figure-skating-anime-1788662926>. 
de debates fecundo, mas também complexo e ainda carente de interlocutores. Por isso, este trabalho assume um caráter mais propedêutico do que necessariamente derradeiro $\mathrm{e}$ conclusivo. A intenção aqui foi tão somente fornecer uma visão geral do tema, apresentando informações e ferramentas conceituais capazes de contribuir com o estabelecimento de novos enfoques e recortes de investigação, no intuito de estimular e, em alguma medida, subsidiar a realização de pesquisas futuras.

\section{REFERÊNCIAS}

ARAÚJO, Allyson Carvalho de. Elementos do pós-moderno na representação do esporte no cinema contemporâneo. 2012. 151f. Tese (Doutorado em Comunicação).- Universidade Federal de Pernambuco, Recife, 2012.

BRACHT, Valter. Sociologia crítica do esporte: uma introdução. ljuí: Editora Unijuí, 2003.

COVELL, Stephen. Religious culture. In: SUGIMOTO, Yoshio. The Cambridge Companion to Modern Japanese Culture. Sydney: Cambridge, 2009. p.147-165.

INGULSRUD, John; ALLEN, Kate. Reading Japan Cool: patterns of manga literacy and discourse. Lanham: Lexington Books, 2009.

INOGUCHI, Takashi. Globalization and cultural nationalism. In: SUGIMOTO, Yoshio. The Cambridge Companion to Modern Japanese Culture. Sydney: Cambridge, 2009. p. 220-233.

KOISHIHARA, Miho. Sports culture. In: SUGIMOTO, Yoshio. The Cambridge Companion to Modern Japanese Culture. Sydney: Cambridge, 2009. p.317-335.

JENKINS, Henry. Cultura da convergência. São Paulo: Aleph, 2009.

LUYTEN, Sonia Bide. Mangá: O poder dos quadrinhos japoneses. São Paulo: Hedra, 2011.

MARTINS, Carlos J. Características do esporte moderno segundo Elias e Dunning. In: SIMPÓSIO PROCESSO CIVILIZADOR, 10., 2007. Campinas. Anais... Campinas: Unicamp, 2007.

MOUER, Ross; NORRIS, Craig. Exporting Japan's culture: from management style to manga. In: SUGIMOTO, Yoshio. The Cambridge Companion to Modern Japanese Culture. Sydney: Cambridge, 2009. p.352-368

MURAKAMI, Haruki. 1Q84. Rio de Janeiro: Alfaguara, 2012.

NORRIS, Craig. Manga, Anime and visual art culture. In: SUGIMOTO, Yoshio. The Cambridge Companion to Modern Japanese Culture. Sydney: Cambridge, 2009. p. 253.

NORRIS, Craig. Images of resistance of manga and anime's improbable objects. Australia. Journal of the Oriental Society of Australia, v. 42, p. 95-114, 2010.

SANTOS, Silvan Menezes dos et al. Estudo da produção científica sobre educação física e Mídia/TICS em Periódicos nacionais (2006-2012). Revista Brasileira de Ciências do Esporte, v. 36, n.2, p.123-139, 2014. 
SUGIMOTO, Yoshio. "Japanese culture": an overview. In: SUGIMOTO, Yoshio. The Cambridge Companion to Modern Japanese Culture. Sydney: Cambridge, 2009. p.1-20

YOSHIMOTO, Banana. Kitchen. New York: Grove, 1988. 